\title{
e CT-Guided Percutaneous Vertebroplasty of the Upper Cervical Spine Via a Translateral Approach
}

Wen-Hao Guo, MD, PhD', Mao-Bin Meng, MD, $\mathrm{PhD}^{2,3}$, Xin You, MD', Yong Luo, MD', Jun Li, MD ${ }^{5}$, Meng Qiu, MD', and Zheng-Yin Liao, MD, PhD ${ }^{1}$

From: ' ${ }^{2}$ Department of Abdominal Oncology, Cancer Center and State Key Laboratory of Biotherapy, West China Hospital, West China Medica School, Sichuan University, No. 37, Guoxue Road, Chengdu 610041, Sichuan Province, People's Republic of China; ${ }^{2}$ Department of Radiation Oncology, Tianjin Medical University Cancer Hospital \& Institute, Tianjin 300060, People's Republic of China; 3 Key Laboratory of Cance Prevention and Therapy, Tianjin Medical University Cancer Hospital

\& Institute, Tianjin 300060, People's Republic of China; ${ }^{4}$ Department of Head and neck Oncology, Cance Center and State Key Laboratory of Biotherapy, West China Hospital, West China Medical School, Sichuan University, No. 37, Guoxue Road, Chengdu 610041, Sichuan Province, People's Republic of China.

${ }^{5}$ Department of anesthesiology and pain management center, West China Hospital, West China Medica School, Sichuan University, No. 37,

Guoxue Road, Chengdu 610041, Sichuan Province, People's Republic of China.

Address Correspondence: Zheng-Yin Liao, MD, PhD Department of Abdominal Oncology Cancer Center and State Key

Laboratory of Biotherapy, West China Hospital, West China Medical School, Sichuan University, No. 37 Guoxue Road, Chengdu 610041, Sichuan Province, People's Republic of China.

E-mail: liaozhengyin@163.com

Disclaimer: There was no externa funding in the preparation of this manuscript.

Conflict of interest: None.

Manuscript received:03/07/2012 Revised manuscript received: $04 / 08 / 2012$

Accepted for publication: 05/17/2012

Free full manuscript: www.pain physicianjournal.com
Background: The clinical management of spinal hemangiomas and osteolytic metastases involving the upper cervical spine (C1-C3) is challenging. Symptoms vary from simple vertebral pain to progressive neurological deficits. Surgery and radiotherapy have been the treatment options for years. Surgery, however, can result in complications, such as hemorrhage, and may be counter-indicated when the treatment goal is primarily palliative due to multiple metastases, an unfavorable prognosis and/or a poor performance state. On the other hand, radiotherapy carries the risk of inducing secondary sarcomas or producing radionecrosis. Percutaneous vertebroplasty (PVP) was recently introduced as an alternative for treating patients in whom surgery and radiotherapy are counter-indicated. As of yet, there are few PVP case reports.

Objective: This study aimed to evaluate the safety and efficacy of PVP using a computed tomography (CT)-guided translateral approach via the space between the carotid sheath and vertebral artery for hemangiomas or metastatic lesions at C1-C3 under local anesthesia.

Study Design: CT-guided PVP was performed in 15 patients with hemangiomas or metastatic lesions at C1-C3 and clinical outcomes were evaluated.

Setting: An interventional therapy group at a medical center in a major Chinese city.

Methods: Fifteen consecutive patients had a total of 15 cervical vertebral bodies treated with CT-guided PVP via a translateral approach. The patients were followed up for a mean postoperative period of 8.3 months (range, 1-40 months). Pain status was assessed using a visual analog scale (VAS). The presence of complications was assessed preoperatively (baseline) and at 24 hours, 2 weeks, and one, 3, 6, 12 and 24 months postoperatively, or until the patient died or was lost to follow-up.

Results: Fifteen consecutive patients were successfully treated with CT-guided PVP via a translateral approach. Their mean VAS score decreased from $7.7 \pm 2.9$ preoperatively to $1.4 \pm$ 1.5 by the 24 hour postoperative time point, and was $1.2 \pm 1.3$ at 2 weeks, $1.2 \pm 1.3$ at one month, $1.4 \pm 1.3$ at 3 months, $0.6 \pm 0.9$ at 6 months, $0.3 \pm 0.5$ at 12 months, and 0 at 24 months after the procedure. The mean VAS score at all of the postoperative time points differed significantly from the preoperative baseline score $(P<0.05)$. No severe complications were observed. Mild complications included 2 cases (13.3\%) of asymptomatic cement leakage into the epidural space, one case $(6.67 \%)$ of anterior leakage from the vertebral body, and 2 cases $(13.3 \%)$ of paravertebral leakage.

Limitations: This was an observational study with a relatively small sample size.

Conclusions: The safety and efficacy of CT-guided PVP using a translateral approach via the space between the carotid sheath and vertebral artery were demonstrated in patients with hemangioma or metastasis in the upper cervical spine. CT-guided PVP via a translateral approach should become a treatment option for such patients.

Key words: CT-guided percutaneous vertebroplasty, upper cervical spine, translateral approach, hemangioma, osteolytic metastasis, pain

Pain Physician 2012; 15:E733-E741 
S pinal lesions include osteolytic metastases and symptomatic hemangiomas. Metastases to the cervical spine are thought to be far less common than those to the thoracic and lumbar spine (1). Metastasis to the upper cervical spine (C1, C2, and (3), especially at the craniovertebral junction, is less common, constituting less than $1 \%$ of all spinal metastases, and the literature is mostly limited to case reports $(2,3)$. Hemangioma of the cervical spine is only occasionally diagnosed in the clinic.

Effective management of upper cervical spinal metastases or hemangiomas using surgery, radiation, and/or percutaneous vertebroplasty (PVP) results in significant pain relief and functional improvement in selected patients (3-5). However, there are no uniform guidelines for the management of symptomatic hemangioma and osteolytic metastasis in the upper cervical spine. Surgery is required for patients with spinal canal compression, acute neurological compromise or impending spinal instability $(5,6)$, but most patients with a normal spinal alignment do not require surgery. In addition, considering the palliative purpose, surgery might not be the best choice, especially in those with multiple metastases, an unfavorable overall prognosis, and/or a poor performance status (6).

The indications for radiotherapy of spinal metastases are pain, impending danger of fracture, neurological compression and prevention of local recurrence (6). Radiotherapy has been used for spinal hemangiomas since 1930. The principal goal of radiotherapy is remineralization of osteolytic bone (4). Significant remineralization can be observed several months after the end of radiotherapy (4). However, radiotherapy can induce secondary sarcomas or the development of radionecrosis (7), and therefore might not be suitable for patients with a poor survival prognosis and a short expected life span.

PVP was initially performed successfully by Galibert et al (8) in 1984 to treat a patient with a symptomatic hemangioma of the axis. The indications for PVP were subsequently extended to the treatment of vertebral compression fractures due to benign or malignant disorders such as osteoporosis, osteolytic metastasis, hemangioma, and multiple myeloma (9-11). PVP is now a well-established procedure comprising a percutaneous injection of a biomaterial, usually polymethyl methacrylate (PMMA), into a vertebral body. In most cases, this procedure significantly relieves pain and stabilizes the vertebral body. PVP of the upper cervical spine, especially $\mathrm{C} 1$ and $\mathrm{C} 2$, remains a challenging procedure that is described in only a few case reports; the procedure has been performed via anterolateral, posterolateral, translateral and direct transoral approaches, under general or local anesthesia (12-26).

Since the study of Huegli et al (13), evidence has emerged to show that PVP could be performed on patients with osteolytic metastasis in C1 via a lateral approach $(13,14)$. However, published descriptions of procedures via a lateral approach are limited to case reports, which cannot guide clinical applications and lack information on the clinical pathway. In addition, because of the rarity of the condition, no large-sample study has evaluated the feasibility, efficacy, or safety of CT-guided PVP through a translateral approach in patients with osteolytic metastases. From 2003 to 2011, we evaluated the feasibility, efficacy, safety, and clinical pathways of CT-guided PVP under local anesthesia through a translateral approach via the space between the carotid sheath and the vertebral artery for the treatment of osteolytic metastasis and hemangiomas in the upper cervical spine.

\section{Methods}

\section{Case Information}

From January 2003 through September 2011, 15 consecutive patients (7 men and 8 women) were treated with PVP under local anesthesia using a computed tomography (CT)-guided translateral approach via the space between the carotid sheath and vertebral artery for hemangiomas or metastatic lesions in the upper spine (C1-C3). The mean age of the study participants was 54 years (range, 30-75 years). A total of 15 vertebral bodies were treated, including 2 hemangiomas and 13 osteolytic metastases ( 2 cases in C1, 9 in C2, and 4 in C3).

All patients included in our cohort presented with neck pain without neurological deficits that was refractory to conservative treatment for at least 12 weeks. The medical and imaging files of each patient were collected and reviewed before the procedure was performed. Primary lesions included spinal hemangiomas and osteolytic metastases from primary carcinoma of the lung, nasopharynx, breast, liver, colon, cervix, and duodenum. The need for CT-guided PVP was confirmed by a multidisciplinary team including orthopedic surgeons, neuroradiologists, medical oncologists, radiation oncologists, and interventional radiologists, aiming for spinal stability and pain relief. Written informed consent was obtained from each patient before the CT-guided PVP procedure. All relevant tests were per- 
formed preoperatively, including blood clotting, CT, and magnetic resonance imaging (MRI). This study was approved by the local ethics committee.

\section{Imaging}

All patients were evaluated before the procedure by enhanced or nonenhanced CT and T1- and T2-weighed short inversion time inversion-recovery MRI. The objectives of CT and MRI were to demon- strate the integrity of the posterior wall of the vertebral body, to determine whether the lesions were osteolytic or osteoplastic (Fig. 1A), to evaluate the invasive range or paravertebral soft tissue, and, most importantly, to determine the positional relationship of the carotid sheath and the vertebral artery (Fig. $1 B$ ) on enhanced CT. After treatment, nonenhanced CT images were obtained immediately to assess the leakage of PMMA.






\section{Procedure}

All procedures were performed in an operating room with a CT scanner. The PVP procedure using a CTguided translateral approach via the space between the carotid sheath and vertebral artery is conceptually illustrated in Fig. 2. The patients were placed in the left or right (usually left) lateral decubitus position on the CT cradle and a soft cushion was put under the neck and shoulder to slightly overextend the cervical spine.
The puncture area was sterilized and local anesthesia of the skin and soft tissues was achieved by injecting $3 \mathrm{~mL}$ of $1 \%$ lidocaine. A single 13-gauge needle was inserted into the skin, along the posterior rim of the carotid sheath and in the direction of the anterior rim of the vertebral artery.

When advanced beyond the internal wall of the carotid sheath on the anteroposterior view, the needle tip may change direction, depending on the rela-

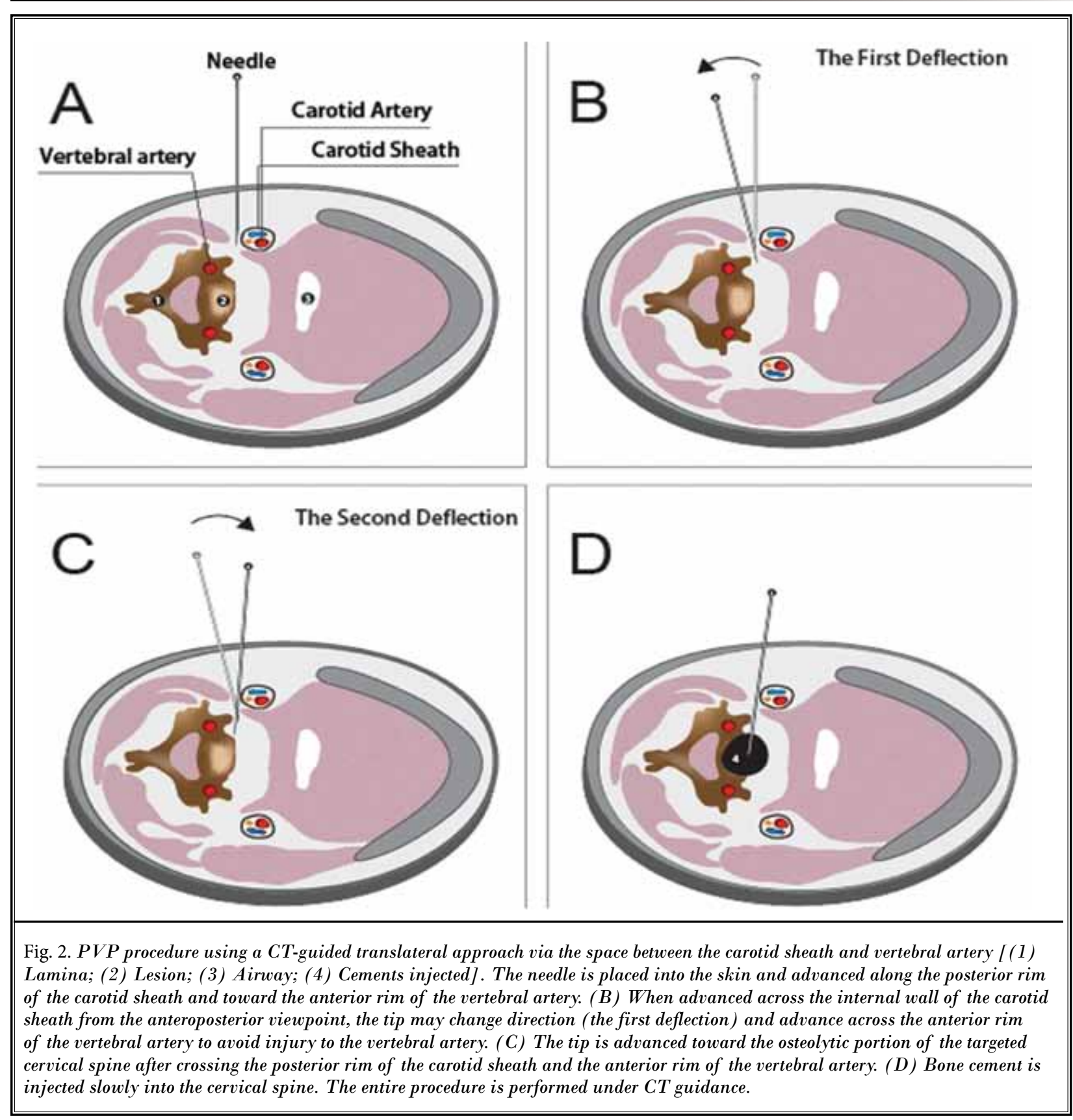


tive positions of the carotid sheath and the vertebral artery. The needle was further advanced beyond the anterior rim of the vertebral artery to avoid injury to the vertebral artery and consequent bleeding. Beyond the posterior rim of the carotid sheath and the anterior rim of the vertebral artery, the needle was advanced toward the osteolytic portion of the targeted cervical spine. Throughout the puncture process, the needle was advanced gradually under $\mathrm{CT}$ guidance, with a slice thickness of one $\mathrm{mm}$, a pitch of $1.5 \mathrm{~mm}$ and a slice increment of $1.5 \mathrm{~mm}$, through the space between the carotid sheath and the vertebral artery until it reached the center of the vertebral body (Figs. 1C-E).

About $0.5 \mathrm{~mL}$ of prepared bone cement (20 g PMMA powder mixed with $10 \mathrm{~mL}$ monomer until suitable for injection) was then injected prior to scanning (Fig. 1F). CT scans were obtained after every injection to monitor the leakage of cement. Cement injection was terminated when the CT showed epidural/intraforaminal leakage or satisfactory filling of the osteolytic region (Fig. 1G). Immediately, a nonenhanced CT scan was then performed to determine the distribution of the cement (Fig. 1H) after withdrawal of the needle and completion of the CT-guided PVP. Antibiotics were administered one day before and for 3 days after the procedure.

\section{Assessment indices}

All patients rated their pain status on a visual analog scale (VAS) before and after the procedure; a score of 0 indicated no pain and a score of 10 represented maximal pain. This rating was repeated 24 hours after the operation. A researcher trained to conduct interviews then contacted the patients to conduct clinical interviews in person, via telephone, or via mail at fixed intervals after their treatment sessions (at 2 weeks and one, 3, 6, 12, and 24 months) or until the patient died or was lost to follow-up. The interviews were used to collect information about treatment response, mainly in terms of degree of pain. The analgesic efficacy of PVP was recorded, based on $50 \%$ or greater improvement in pain versus baseline. All complications of the procedure, including severe complications (i.e., pulmonary embolism, septic shock, cardiogenic failure, respiratory failure, or death) and mild complications (i.e., infection and asymptomatic cement leakage) were recorded in this series.

\section{Statistical analysis}

Data are presented as means \pm standard deviations.
The results at all of the study time points were analyzed using Student's t-test with SPSS statistical software, version 11.5 (SPSS, Chicago, IL). $P<0.05$ was considered statistically significant.

\section{Results}

CT-guided PVP via a translateral approach was successfully performed in 15 patients (seven men and eight women). All procedures were completed within 30-40 min. A mean volume of $1.55 \mathrm{~mL}$ cement was injected in C1 (range, 1.1-2.0 mL), with little extraosseous reflux leakage. The mean amount of cement injected into C2 was $1.8 \mathrm{~mL}$ (range, $1.3-2.0 \mathrm{~mL}$ ), and a mean of $1.95 \mathrm{~mL}$ was injected into $\mathrm{C} 3$ (range, $1.5-2.2 \mathrm{~mL}$ ). All of the upper cervical vertebral bodies were filled satisfactorily. Asymptomatic cement leakage was detected in the epidural space in 2 patients, anteriorly from the vertebral body in one patient and paravertebrally in 2 patients. None of these 5 patients had clinical symptoms related to the procedure. No severe complications were discovered during a 24 month follow-up period. Three patients were lost to follow-up 3 months after the procedure.

VAS scores decreased from $7.7 \pm 2.9$ preoperatively to $1.4 \pm 1.5$ by 24 hours after the operation. The VAS scores remained low throughout the follow-up period: $1.2 \pm 1.3$ at 2 weeks, $1.2 \pm 1.3$ at one month, $1.4 \pm 1.3$ at 3 months, $0.6 \pm 0.9$ at 6 months, $0.3 \pm 0.5$ at 12 months, and $0 \pm 0$ at 24 months. Mean VAS differed significantly from the preoperative baseline at each postoperative time point. All $P$ values were $<0.05$ (Table 1).

\section{Discussion}

Our findings showed an important improvement in the management of patients with symptomatic hemangiomas or osteolytic metastases in the upper cervical spine (C1, C2, or C3). From January 2003 through September 2011, 15 patients were successfully treated with CT-guided PVP through a translateral approach via the space between the carotid sheath and the vertebral artery. No severe complications were observed during a 24 month follow-up period. Asymptomatic cement leakage was detected in 5 of the 15 patients. Analgesia was achieved by PVP in most patients in this series, similar to the findings in other reports of this procedure. This translateral approach was thus shown to be feasible, safe and effective. We report here the operative procedure and thereby provide a clinical pathway for patients with hemangiomas or metastatic lesions in the upper cervical spine. 


\section{Comparison with other studies}

Management of spinal hemangiomas and osteolytic metastases in the upper cervical spines is a clinical challenge. The primary end points are palliative, to achieve pain relief and restore spinal stability, to improve or maintain neurologic function, and to obtain local cancer control (5). Because approximately $90 \%$ of metastatic tumor deposits are found in the ventral portion of the spine (5), the principal method of surgical treatment is ventral decompression with corporectomy, vertebral body replacement, and ventral stable-angle plate osteosynthesis. In addition, evidence from clinical series has confirmed the role of posterior instrumentation in providing durable fixation (27-32). However, most patients with normal spinal alignment do not require surgery. Furthermore, considering the palliative aims, surgery might not be the best choice, especially in those with multiple metastases, an unfavorable overall prognosis and/or poor performance status (5).

Radiotherapy is another proven modality in the management of spinal hemangiomas and osteolytic metastases in the cervical spine. Various regimens have been compared in randomized trials, including singleand multi-fraction regimens (4). Substantial pain relief is reported in $60-90 \%$ of cases, but pain relief takes 10 14 days after the start of radiotherapy in $70 \%$ of patients (5). The role of radiotherapy in relieving pain is limited by the sensitivity of tumor cells to ionizing radiation, the long time taken to achieve its effects, and its role in stabilizing the vertebral body. Remineralization, which is pivotal for the prevention and treatment of pathologic fractures, is more commonly observed in multi-fraction regimens than in single-fraction regimens (4). Remineralization of osteolytic metastases can be observed 2-3 weeks after radiotherapy (20-30 Gy) and reaches its peak at 2 months (5). Therefore, radiotherapy might not be suitable for patients with a poor survival prognosis or short expected life span. In summary, the roles of surgery and radiotherapy are limited in patients with spinal hemangiomas or osteolytic metastases of the upper cervical spine.

\section{Comparison with other approaches}

The cervical vertebrae are located deeper than the thoracic and lumbar vertebrae. Compared with the transpedicular approach commonly used in the thoracic and lumbar spine, all other approaches in the cervical spine are more difficult due to potentially dangerous complications related to the carotid sheath and the vertebral artery. In addition to its use in treating osteoporotic vertebral fractures, PVP has gained popularity for the relief of pain due to tumoral osteolysis and spinal hemangiomas by stabilizing the cervical vertebrae, as in the thoracic and lumbar vertebrae (5-7). Since the 2002 study of Wetzel et al (12), which was the first report of PVP of C1, and the 2000 study of Tong et al (17), which was the first report of PVP of C2, evidence has emerged to show that PVP of C1 through a translateral approach and C2 through a transoral approach can be performed safely and with satisfactory clinical results. However, studies have been limited to case reports and thus lack details on the clinical pathway for treating such patients. Here, we summarize and compare all PVP approaches, except the conventional transpedicular approach.

\section{Anterolateral approach $(12,14,22)$}

This approach requires appropriate overextension of the cervical part of the spine. The carotid sheath is located and then pushed laterally. The needle tip is placed approximately one $\mathrm{cm}$ beneath the mandibular angle between the carotid sheath and the trachea. Attention should be paid to avoiding injuries to the submandibular gland, carotid artery, jugular vein, and cranial nerves during the procedure. The anterolateral approach can be used under local anesthesia, but in our experience, maintaining overextension is difficult for obese patients and for those in severe pain. In such cases, the anterolateral approach is still possible, but it is more difficult due to the increased oblique angle and the distance through which the needle must be passed.

\section{Transoral approach $(17-21,23,25,26)$}

The transoral approach is the most direct route for

Table 1. VAS scores of patients of at pre-and each post-operative time of follow-up.

\begin{tabular}{|c|c|c|c|c|c|c|c|c|}
\hline & Pre-op & $\begin{array}{c}\text { Post-op 24 } \\
\text { hours }\end{array}$ & $\begin{array}{c}\text { Post-op 2 } \\
\text { weeks }\end{array}$ & $\begin{array}{c}\text { Post-op one } \\
\text { month }\end{array}$ & $\begin{array}{c}\text { Post-op } \\
\text { 3 months }\end{array}$ & $\begin{array}{c}\text { Post-op } \\
\text { 6 months }\end{array}$ & $\begin{array}{c}\text { Post-op } \\
\text { 12 months }\end{array}$ & $\begin{array}{c}\text { Post-op } \\
\text { 24 months }\end{array}$ \\
\hline & $(\mathrm{N}=15)$ & $(\mathrm{N}=15)$ & $(\mathrm{N} 15)$ & $(\mathrm{N}=15)$ & $(\mathrm{N}=8)$ & $(\mathrm{N}=5)$ & $(\mathrm{N}=4)$ & $(\mathrm{N}=3)$ \\
\hline Mean $\pm \mathrm{SD}$ & $7.7 \pm 2.9$ & $1.4 \pm 1.5$ & $1.2 \pm 1.3$ & $1.2 \pm 1.3$ & $1.4 \pm 1.3$ & $0.6 \pm 0.9$ & $0.3 \pm 0.5$ & 0 \\
\hline $\begin{array}{c}\text { Versus } \\
\text { Preop }\end{array}$ & & $P=0.00001$ & $P=0.00001$ & $P=0.00001$ & $P=0.00001$ & $P=0.00001$ & $P=0.0001$ & $P=0.00004$ \\
\hline
\end{tabular}


PVP of C2, with less strict body position requirements. The visual field in the pharyngo-oral cavity is widened using a diastomotris and retractor. The puncture is performed directly after tracheal intubation. This procedure generally has to be performed under general anesthesia and the postoperative infection rate is potentially higher than that of the anterolateral approach, so prophylactic antibiotics are used routinely.

\section{Posterolateral approach $(12,15,24)$}

Under local or general anesthesia, the needle is inserted through the posterior cervical space and advanced in the anterior, cranial, and medial direction. The posterolateral approach has the advantage that lesions in the lateral mass and the posterior arch of the atlas are aligned with the access route. However, there is a risk of injury to the vertebral artery. In addition, this route is not suitable for lesions in the anterior arch of the cervical spine.

\section{Translateral approach $(13,14)$}

There are only 2 pertinent reports in the literature of PVP of C1 via a translateral approach. Both procedures used combined fluoroscopic and CT guidance. In our study, we reviewed the cross-sectional anatomy and CT of the cervical spine to identify a potential internal space between the carotid sheath and the vertebral artery lateral to the C1-3 level. However, the placement of the needle directly through this space may not be possible in some patients due to anatomical variations in its location. In such circumstances, the needle could be turned oblique to the posterior surface of the carotid sheath, and then turned slightly to the anterior side to create sufficient space. This procedure can be performed under local anesthesia, and does not have strict body position requirements. Under local anesthesia the patient can speak to the operator throughout the procedure, allowing immediate detection of any neurological symptoms or complications. However, this approach still has some limitations: 1) the use of CT guidance precludes continuous observation. It is critical that the operator take great care as the needle is advanced, moving slowly and making step-by-step adjustments to avoid injury to the great vessels; 2) when guided by $\mathrm{CT}$, the procedure takes longer; and 3) the bone cement polymerizes rapidly. We added Lipiodol Ultra-fluide (Guerbet 16-24, Aulnay-Sous-Bois, France) to the cement to prolong the time it existed as a flowing mixture from 1.5-2.5 minutes to 4-7 minutes, which is an adequate time for injection.
Postoperative observation showed no severe complications. Pain and vertebral stability were significantly improved. Although there are risks of complications, PVP of the upper cervical spine can be successful with experienced and careful operational skills and safe operative routes.

\section{Strengths and limitations of study}

We recognize several limitations to our study. First, in this observational study our patients were recruited from a single center, and the sample size was small, mainly due to the scarcity of cases of hemangioma or metastasis of the upper cervical spine. Second, some patients died during the follow-up period. Although we doubt that these deaths impair the generalizability of our findings, other interventional or pain management centers need to examine the safety, feasibility, and efficacy of PVP in a larger population. Finally, we did not perform an arm-to-arm study, comparing CT-guided PVP with surgery or radiotherapy.

This study highlights the safety, feasibility, and efficacy of CT-guided PVP by a translateral approach. No study has compared CT-guided PVP with surgery or radiotherapy. In this observational study, CT-guided PVP by a translateral approach via the space between the carotid sheath and the vertebral artery can lead to significant pain relief without severe complications.

\section{Conclusions}

There are several implications of our study. Although PVP does not represent a cure for osteolytic cervical metastasis, significant pain relief is a principal goal of PVP, similar to other treatment strategies. In our study, pain was relieved significantly. In conclusion, we have shown that CT-guided PVP by a translateral approach via the space between the carotid sheath and the vertebral artery is safe, feasible, and effective in the treatment of patients with hemangiomas or osteolytic metastasis in the upper cervical spine. It is especially suitable for obese or short-necked patients with lesions in the anterior arch, and for those in whom an anterolateral/posterior/transoral approach is unsuitable. However, familiarity with local anatomy, experience, and skill are prerequisites for success. Our findings will help to inform physicians of the appropriate management of their patients.

\section{Conflicts of Interest}

No support from any organization for the submitted work; no financial relationships with any organiza- 
tions that might have an interest in the submitted work in the previous 8 years; no other relationships or activities that could appear to have influenced the submitted work.

\section{Acknowledgements}

Based on rigorous scientific attitude as proposed by the guidelines on authorship established by the International Committee of Medical Journal Editors statement on Authorship and Contribution, Dr. MaoBin Meng, MD, PhD, Department of Radiation Oncol- ogy, Key Laboratory of Cancer Prevention and Therapy, Tianjin Medical University Cancer Hospital \& Institute, actively participated in the entire process of this manuscript including Conception and design, Collection and assembly of data, Data analysis and interpretation, Manuscript writing and revising, and Final approval of manuscript. Given his outstanding contribution to this manuscript, I and other authors unanimously authorized Dr. Mao-Bin Meng and Dr. Wen-Hao Guo as the Co-first author. We thank Medjaden Bioscience Limited for assisting in the preparation of this manuscript.

\section{References}

1. Pilge $\mathrm{H}$, Holzapfel BM, Prodinger PM, Hadjamu M, Gollwitzer H, Rechl H. Diagnostics and therapy of spinal metastases.[Article in German] Orthopade 2011; 40:185-193.

2. Sherk HH. Lesions of the atlas and axis. Clin Orthop Relat Res 1975; 109:33-41.

3. Hugh D. Moulding, Mark H. Bilsky. Metastases to the craniovertebral junction. Neurosurgery 2010; 66:113-118.

4. Rades D, Schild SE, Abrahm JL. Treatment of painful bone metastases. Nat Rev Clin Oncol 2010; 7:220-229.

5. Boschi V, Pogorelic Z, Gulan G, Perko Z, Grandic L, Radonic V. Management of cement vertebroplasty in the treatment of vertebral hemangioma. Scand J Surg 2011; 100:120-124.

6. Delank KS, Wendtner C, Eich HT, Eysel P. The treatment of spinal metastases. Dtsch Arztebl Int 2011; 108:71-79.

7. Guedea F, Majó J, Guardia E, Canals E, Craven-Bartle J. The role of radiation therapy in vertebral hemangiomas without neurological signs. Int Orthop 1994; 18:77-79.

8. Galibert P, Deramond H, Rosat P, Le Gars D. Preliminary note on the treatment of vertebral angioma by percutaneous acrylic vertebroplasty. [Article in French] Neurochirurgie 1987; 33:166-168.

9. Barragán-Campos HM, Vallée JN, Lo D, Cormier E, Jean B, Rose M, Astagneau $P$, Chiras J. Percutaneous vertebroplasty for spinal metastases: Complications. Radiology 2006; 238:354-362.

10. Cotten A, Dewatre F, Cortet B, Assaker $R$, Leblond D, Duquesnoy B, Chastanet $\mathrm{P}$, Clarisse J. Percutaneous vertebroplasty for osteolytic metastases and myeloma: Eeffects of the percentage of lesion filling and the leakage of methyl meth- acrylate at clinical follow-up. Radiology 1996; 200:525-530.

11. Murphy KJ, Deramond H. Percutaneous vertebroplasty in benign and malignant disease. Neuroimaging Clin N Am 2000; 10:535-545.

12. Wetzel SG, Martin JB, Somon T, Wilhelm $\mathrm{K}$, Rufenacht DA. Painful osteolytic metastasis of the atlas: Treatment with percutaneous vertebroplasty. Spine (Phila Pa 1976) 2002; 27:E493-495.

13. Huegli RW, Schaeren S, Jacob AL, Martin JB, Wetzel SG. Percutaneous cervical vertebroplasty in a multifunctional imageguided therapy suite: Hybrid lateral approach to $\mathrm{C}_{1}$ and $\mathrm{C}_{4}$ under $\mathrm{CT}$ and fluoroscopic guidance. Cardiovasc Intervent Radiol 2005; 28:649-652.

14. Anselmetti GC, Manca A, Chiara G, Regge $D$. Painful osteolytic metastasis in volving the anterior and posterior arches of $\mathrm{C}_{1}$ : Percutaneous vertebroplasty with local anesthesia. J Vasc Interv Radiol 2009; 20:1645-1647.

15. Dang D, Baig MN, Christoforidis G, Chiocca $E A$, Gabriel J. $C_{2} / C_{3}$ pathologic fractures from polyostotic fibrous dysplasia of the cervical spine treated with percutaneous vertebroplasty. Eur Spine J 2007; 16:250-254.

16. Christoforidis G, Dang D, Gabriel J. Catheter-Directed Percutaneous yranspedicular $\mathrm{C}_{2}-\mathrm{C}_{3}$ vertebroplasty in a patient with fibrous dysplasia using seldinger technique. AJNR Am J Neuroradiol 2006; 27:1738-1740.

17. Tong FC, Cloft HJ, Joseph GJ, Rodts GR, Dion JE. Transoral approach to cervical vertebroplasty for multiple myeloma. AJR Am J Roentgenol 2000; 175:1322-1324.

18. Anselmetti GC, Regge D, Sardo E, Manca A, Cirillo S, Meloni T, Debernardi F. Min- imally invasive treatment of $\mathrm{C}_{2}$ odontoid traumatic fracture with transoral percutaneous vertebroplasty. Eur Radiol 2007; 17:850-851.

19. Mont'Alverne F, Vallée JN, Cormier E, Guillevin R, Barragan $H$, Jean B, Rose $M$, Chiras J. Percutaneous vertebroplasty for metastatic involvement of the axis. AJNR Am J Neuroradiol 2005; 26:16411645 .

20. Martin JB, Gailloud P, Dietrich PY, Luciani ME, Somon T, Sappino PA, Rüfenach DA. Direct transoral approach to $\mathrm{C}_{2}$ for percutaneous vertebroplasty. Cardiovasc Intervent Radiol 2002; 25:517-519.

21. Reddy AS, Hochman M, Loh S, Rachlin J, Li J, Hirsch JA. CT guided direct transoral approach to $C_{2}$ for percutaneous vertebroplasty. Pain Physician 2005; 8:235-238.

22. Yoon JY, Kim TK, Kim KH. Anterolateral percutaneous vertebroplasty at $\mathrm{C}_{2}$ for lung cancer metastasis and upper cervical facet joint block. Clin J Pain 2008; 24:641-646.

23. Rodriguez-Catarino M, Blimark C, Willén J, Mellqvist UH, Rödjer S. Percutaneous vertebroplasty at $\mathrm{C}_{2}$ : Case report of a patient with multiple myeloma and a literature review. Eur Spine ] 2007; 16:242-249.

24. Sun HY, Lee JW, Kim KJ, Yeom JS, Kang HS. Percutaneous intervention of the $\mathrm{C}_{2}$ vertebral body using a CT-guided posterolateral approach. AJR Am J Roentgenol 2009; 193:1703-1705.

25. Sachs DC, Inamasu J, Mendel EE, Guiot $\mathrm{BH}$. Transoral vertebroplasty for renal cell metastasis involving the axis: Case report. Spine (Phila Pa 1976) 2006; 31:E925-928.

26. Krüger A, Schnabel M, Hegele A, Ruch- 
holtz S, Stiletto R. Transoral vertebroplasty: An alternative for operative treatment of metastases of the upper cervical spine. [Article in German] Unfallchirurg 2009; 112:426-432.

27. Saliou G, Kocheida el M, Lehmann P, Depriester C, Paradot G, Le Gars D, Balut $A$, Deramond H. Percutaneous vertebroplasty for pain management in malignant fractures of the spine with epidural involvement. Radiology 2010; 254:882-89o.

28. Hastings DE, Macnab I, Lawson V. Neoplasms of the atlas and axis. Can J Surg 1968; 11:290-296.

29. Sundaresan N, Galicich JH, Lane JM, Greenberg HS. Treatment of odontoid fractures in cancer patients. J Neurosurg 1981; 54:187-192.

30. Jackson RJ, Gokaslan ZL. Occipitocervicothoracic fixation for spinal instability in patients with neoplastic processes. J
Neurosurg 1999; 91:81-89.

31. Bilsky MH, Shannon FJ, Sheppard S, Prabhu V, Boland PJ. Diagnosis and management of a metastatic tumor in the atlantoaxial spine. Spine 2002; 27 :1062-1069.

32. Fourney DR, York JE, Cohen ZR, Suki D, Rhines LD, Gokaslan ZL. Management of atlantoaxial metastases with posterior occipitocervical stabilization. J Neurosurg 2003; 98:165-170. 
